\title{
ARTÍFICES Y TASADORES DE LA CAPILLA DE NUESTRA SEÑORA DE LA CONCEPCIÓN, MÁS CONOCIDA COMO CAPILLA DEL MILAGRO DE LAS DESCALZAS REALES (1678) *
}

Recientemente hemos puesto de relieve, mediante la localización de unas cartas de pago, la participación de Dionisio Mantuano con Francisco Rizi en la realización de las pinturas murales que decoran la Capilla del Milagro de las Descalzas Reales de Madrid ${ }^{1}$. Sin embargo, debido a la parquedad de los documentos en cuanto a la adjudicación exacta de lo que había realizado cada artista (y ante la falta de cualquier otro tipo de documento), sólo se podía sugerir que Mantuano pudo ser el encargado de realizar las perspectivas o arquitecturas fingidas, mientras que todo lo estrictamente figurativo lo atribuíamos a la mano de Rizi. Con el presente artículo, lo que pretendemos es por una parte, corroborar documentalmente dichas afirmaciones precisando aún más la labor que ambos artistas desarrollaron tanto en el interior como en el exterior de la Capilla. Por otro lado, dejar apuntadas algunas noticias sobre el resto de los artífices que trabajaron en ella y de los pintores que tasaron y valoraron esta destacada obra de la pintura mural madrileña del siglo XVII, como fueron en un primer momento Francisco Rizi (cuya memoria de tasación no se conserva) y más tarde Joseph Donosso y Claudio Coello, Pedro de Villafranca y Bartolomé Pérez.

Es la propia Sor Margarita de la Cruz, monja del Monasterio e hija del fundador de la Capilla don Juan José de Austria, quien remitió en torno a 1680, una carta hológrafa a la Junta de Testamentaría de su padre (muerto en 1679) ordenando que se diera satisfacción económica al pintor Dionisio Mantuano por todo lo que había trabajado «en la Capilla Antigua de $N$. Sra del Milagro y demas adornos que hizo fuera de la capilla nueba». Junto a la carta, incluyó la memoria del propio pintor donde se recoge de forma pormenorizada, las obras que allí realizó ${ }^{2}$. Por ellas Mantuano solicitaba seis mil cien reales de vellón. Esta cantidad, a juicio de uno de los ayudas de cámara y guardajoyas de don Juan José ${ }^{3}$, era «exhorbitante», por lo que él mismo sugería en su informe a la Junta de Testamentaría que: «para justificar esta materia podrían los señores de la Junta mandar siendo servidos se tasse dha obra por personas de su facultad con asistencia nra para dezir lo que hizo de mas de lo que esta satisfecho». En conformidad con ello se solicitó una tasación de la obra, la cual recayó en dos pintores: Joseph Donosso y Claudio Coello ${ }^{4}$. Gracias a esta tasación, que incluimos en el apéndice II, y su cotejo con el memorial de Dionisio Mantuano en el apéndice I, podemos saber con más precisión lo que el Boloñés pintó en las Descalzas Reales.

En lo relativo al interior de la capilla propiamente dicha, se corrobora que trabajó en la ejecución de las pinturas murales «al fresco y al olio», "cornisas abaxo» en la parte que corresponde a las «dos prospetivas en los dos testeros del balcon de hierro, (hace referencia a

* Este artículo es parte integrante de la Tesis Doctoral que estamos realizando sobre: «Don Juan José de Austria y su relación con el arte y la cultura del siglo XVII».

1 González Asenjo, Elvira: «Dionisio Mantuano pintor en la Capilla del Milagro de las Descalzas Reales de Madrid», Reales Sitios, n. ${ }^{\circ} 138,1998$, pp. 75-76.

2 Memoria de lo atrasado por la colocacion de N. Sra. del Milagro en su Capilla nueba nel Real conbento de las Señoras Descalças Reales, de los adornos de afuera de la sudha Capilla nueba hechos d'orden de SA el Sr Don Juan de Austria que goçe de gloria. A.C.S. Csr, leg. 193. Incluido en el Apéndice I.

3 A.G.S. Csr. leg. 193. Carta de Don Joseph de Peramata y Alcántara.

4 Tasaron la obra el 25 de abril de 1681. Estos pintores trabajaban de forma conjunta habitualmente. Véase a este respecto Sullivan, Edward, J.: Claudio Coello y la Pintura Barroca Madrileña, Madrid, 1989. Por otro lado es curioso comprobar como Claudio Coello sólo unos años más tarde (el 30 de marzo de 1683) ocuparía precisamente el puesto de Pintor del rey vacante tras la muerte del propio Dionisio Mantuano. 
la tribuna interna de la capilla), que mira nel patio del refetorio que son pintadas al fresco». También se sabe que colocó «unos yerros a una campanilla (de truenos) dorados a fuego».

Lo que resulta más interesante es que igualmente trabajó en la renovación y aderezo de la "Capilla vieja de Nra Sra del Milagro que sirve ahora a N. Sra de la Concepción, pintada al fresco y al oleo con un nicho nuobo pintado y la peana de nuobo hecha dorada y pintada», además del «aderezo de una ventana». Gracias a esta noticia, se pone de relieve por primera vez, que la nueva capilla fundada por don Juan en 1678 cambió de nombre y dejo de denominarse Capilla del Milagro, porque tal y como se indica en varias ocasiones «sirve ahora a N. Sra de la Concepción». Precisamente por ello cobra tanta importancia el nicho y la peana que hizo Mantuano para Nuestra Señora de la Concepción, los cuales bien pueden aludir a un conjunto (en cualquier caso hoy perdido) que podrían haber estado situados en el muro donde se asienta el retablo, a la altura del banco de estructura cajeada (precisamente la que más difiere con el resto del entramado) o incluso en la calle central del cuerpo del retablo donde hoy está una copia del cuadro de la Virgen del Milagro (y por tanto ocupando su lugar). Por último, en su memoria también se pone de relieve que compuso "l'altar con (a)lacenas y añadir a los lados dho altar y dorado de nuevo los filetes de nuevo». En relación con este altar o ara, Sor Margarita de la Cruz, refiere en una de las cartas sus dudas con respecto a ella y así expresa a la Junta que: «desseo saber si la ara que VMd, me trajo era consagrada porque por esta duda no me e atrevido a que digan misa en ella».

En el exterior de la Capilla, tal y como consta en los memoriales, intervino en la ejecución de los zócalos decorativos o rrodapies que imitando mármol (de xaspes de tortosa y berdes con enbutidos de lapislazuli y betas de oro barniçados) recorren la pared lateral externa de la Capilla de Nazaret y por tanto se sitúan en el pasillo de ingreso a la del Milagro ${ }^{5}$. Toda esta labor pictórica que Dionisio desarrolló en las Descalzas: (perspectivas, peana, altar y rodapié), fue finalmente valorada y tasada por José Jiménez Donoso y Claudio Coello en «tres mil novecientos y catorce reales de vellón», una cantidad inferior a la propuesta por Mantuano pero que sabemos que percibiría finalmente en su totalidad ${ }^{6}$, esto es «zientto $y$ treinta y tres mill y settentta y sies mrs de vellon» ${ }^{7}$.

Francisco Rizi, además de ayuda de la furriera y pintor del rey Carlos II, ahora sabemos con total certeza que fue pintor de cámara de don Juan José de Austria ${ }^{8}$, por lo que participó de forma activa en la realización de la nueva Capilla. Al igual que Mantuano tuvo problemas para que se le retribuyera lo adeudado por su trabajo de pintor y tasador en la Capilla, (entre otras cosas) ${ }^{9}$, por lo

5 Dichos zócalos son exactamente iguales a los que presenta la Capilla de Nazaret y la Capilla de la Dormición en el mismo Monasterio, tal y como ha señalado Ruiz Alcón, M. T.: «Capilla de la Dormición y Casita de Nazaret», Reales Sitios, n. ${ }^{\circ} 22,1969$, pp. 53-60.

${ }^{6}$ Tras la resolución de la Junta Testamentaria del 19 de julio de 1681, Las dos tercias partes de los tres mil nuevecientos y catorze reales de vellon en que se tasso esta obra se libren en alajas de la almoneda...» A.G.S., csr, leg. 193.

7 González Asenjo, Elvira: Op. cit.

8 Francisco Rizi, tras la muerte de don Geronimo de la Cruz y Mendoza, juró el cargo de pintor de cámara de don Juan sin goces ante el Conde de Villamanrique el 17 de enero de.1678, puesto en el que permanecería hasta el 17 de septiembre del 1679 fecha en la que falleció don Juan. (A.G.S., csr, leg. 193).ç

9 Reclama también que se le satisfaga la labor que hizo de tasar las pinturas de la almoneda de don Juan José de Austria, por la que finalmente se le libra el 26 de mayo de 1683, 120784 mrs. También reclama a la Junta por todo el tiempo que sirvio como pintor de cámara a don Juan José de Austria y que considera de mas apremio que «diez. mil doblones». Explica cómo «el amor grande que tiene y ha tenido a su Alteza no le permite pedir merced por ello y así lo deja en perpetuo silenzio, (pero) ahora por estar con mucha necesidad se contenta con que esto que pide sea en ropa de almoneda por lo que estubiere tasada». Parece ser que Rizi fue pintor de cámara de SA «sin goze», pero «fue del animo de SA se le supliese en aiudas de costa por la secretaria el goze que no 
cual expidió varias memorias a la Junta de Testamentaría, reclamando lo que se le debía ${ }^{10}$ por encontrarse como el decía: «con mucha necesidad». Pero por desgracia, aunque fue él, el encargado de tasar toda la obra «del adorno interno de la Capilla de Nuestra Señora del Milagro ...», (y que desarrollaremos después) no tasó la parte más importante de su propio trabajo, por lo que no hay constancia escrita de lo que hizo en la capilla en lo relativo a la pintura figurativa mural o la pintura del ático del retablo. La razón de este comportamiento, queda explicada en uno de los memoriales, en donde se refiere que «en un billete aparte represento a Vmd (la Junta Testamentaria) su desinteres, y deseo de no exceder del decreto y que ningun arifice llevase un maravedí que no fuesse con todo ajuste de conciencia». Sin embargo, parece ser que cambió de idea y así: «con mortificazion y berguenza suplico a vmd insinuase a su Alteza, en el mas deçente estilo, si le parecía podía merecer lo que Mantuano aunque la parte de don Francisco Rizi era mayor, de mas empeño costa y difcultad». Efectivamente a Rizi se le debió tasar filnalmente parte de su obra, sin precisar cuál y cuánta, porque queda indicado como «la estimazión de la pintura, que toco al dicho don Francisco se le dio ygual balor a la de Don Dionissio Mantuano».

De todos modos, hubo otras pinturas'sueltas que Rizi hizo para la capilla y que tampoco «se incluieron en la primera tasación que se hizo para el efecto de pagar las obras». Se trata de las obras que «por mandado de» las monjas del monasterio se encargaron al pintor, al cual no le pagaron y en cambio le remitieron a la Junta de Testamentaría de don Juan José. Tal y como se explica en uno de los memoriales: "y creyendo ser obra que corria fuera de la tasaxion de todo lo demas lo dejo a la satisfacion del Real Conbento y ahora las Señoras descalzas le remiten a el almoneda importando su valor no mas que dos mil seiscientos y quarenta reales». Disconforme con ello, Rizi, presentó a la Junta un documenţ"notarial con la tasación de dichas obras (apéndice III), con fecha del 18 de noviembre de 1680 y firmado en esta ocasión por los pintores Pedro de Villafranca ${ }^{11}$ y Bartholomé Pérez ${ }^{12}$.

Allí se certifica que son suyas las «nueve pinturitas que hico para la Capillita del Santo Cristo que esta en la Capilla del Milagro». La mencionada capillita es un pequeño cubículo dentro de la del Milagro situado en el lado de la Epístola, desde el que arranca la escalera de acceso a la tribuna. Tal y como reza el memorial se hizo «para colocar un Santo Christo grande de marfil que SA tenia en su alcoba». Corroborando en parte lo que ya adelantó Diego Angulo ${ }^{13}$, ocho de las nueve pin-

se expresó en la merced». Sin embargo, «como no logró la dicha de goçarlas por aver fallecido (don Juan José), al mejor tiempo», reclama que se le pague "cien ducados de gages y quinientos reales de cassa de aposento al año», que hacen un total de «dos mil seiscientos y ochenta y seis reales». (A.G.S., csr, leg. 193).

10 Recogido por una parte en la Memoria de don Antonio Ortiz de Otalora en donde expone las súplicas de Francisco Rizi (17 de octubre de 1680), también por la Memoria de tasación de pinturas firmada por Bartolomé Pérez y Pedro de Villafranca (18 de noviembre de 1680), junto a los papeles de inspección del Contralor don Manuel Rodríguez (20 de noviembre de 1680). (Todo en A.G.S., csr, leg. 193).

"I Sobre Pedro de Villafranca como grabador y pintor: Barrio Moya, José Luis: «Pedro de Villafranca y Malagón, pintor y grabador manchego del siglo XVII», Cuadernos de Estudios Manchegos, 13, 1982, pp. 105122. Collar de Cáceres, Fernando: «Un retablo inédito de Pedro de Villafranca», Cuadernos de Estudios Manchegos, 1990. McDonald, Mark: Studies in printmarking and print collecting in Madrid, 1584-1684 and the contribution of Pedro de Villafranca y Malagón, University of Melbourne, 1996, Tesis doctoral. Pintor del que hasta ahora no se tenían noticias de su actividad como tasador. Valdivieso, Enrique: «Dos guirnaldas firmadas por Bartolomé Pérez, A.E.A., n.ํ 282, 1998, pp. 151-152; Pérez Sánchez, Alfonso: Juan de Arellano 1614-1676, Madrid, 1998; Cherry, Peter: «New documents of Bartolomé Pérez», Apollo, march 1995.

12 Según el cual presenta una fuerte participación de taller. Angulo Iñiguez, Diego: «Francisco Rizi, Pinturas Murales», A.E.A., 1974, p. 372.

13 Como son la oración del Huerto, el Prendmiento, el Ecce Homo, el Cristo a la Columna, el Camino del Calvario, Cristo clavado en la Cruz, la Piedad y la Aparición del Salvador a la Virgen. 
turas a las que se hace referencia son las situadas en las hojas de las puertas de la capillita, donde se representan diversas escenas de la Pasión ${ }^{14}$, obedeciendo a una, temática por la que la orden franciscana sintió desde siempre una profunda devoción ${ }^{15}$. La otra pintura aludida es: «Una ymajen de Nra Sra, San Juan y la Magdalena» que debe ser la situada al fondo de la capillita de «siete quartas de alto» y que fue tasada de forma más elevada en «setecientos reales de vellon» frente a los ocho escenas de la pasión (de «media vara de alto» que se tasaron en «ducientos reales cada uno».

En colaboración con Mantuano, Francisco Rizi, trabajó en la decoración del pasillo de ingreso a la Capilla. Rizi realizó los «seis quadros pintados al olio en la pared que hace paso al dho oratoria que tendrian cada uno de alto como siete quartos los quales se tasaron cada una a quinientos reales de vellon» ${ }^{16}$. Los cuadros a los que hace alusión son los situados en el muro lateral externo de la Capilla de Nazaret, los que están más próximos y colindantes con la del Milagro. Son respectivamente, cuatro figuras de Santos sobre fondo rojo y cartelas con los nombres de San Cristóbal, San Antonio de Padua, San Sebastián y San Bernardo. Por otro lado en el muro contrario, justo en la pared externa al lado de la puerta del Milagro hay dos imágenes de dos Santas: Santa Ana y Santa Isabel. Estas quince pinturas de Rizi, (las nueve de la capilla y las seis externas) fueron tasadas por Villafranca y Bartolomé Pérez en «cinco mil y trescientos reales de vellon».

Francisco Rizi, también reclamaba a la Junta su trabajo como tasador de las obras de la Capilla del Milagro. Labor en al que «empleo y ocupó con mucho afan y diligenzia mas de un mes de tiempo». Tal y como indica Rizi debió de recibir el encargo del propio don Juan José y «aunque se componía de facultades distintas, el crédito que tenia ganado con Su Alte$z a$ en la parte de la verdad y concienzia, lo suplio todo». Por desgracia, no se conserva la memoria de tasación de Rizi, sin embargo se pueden tener algunas noticias acerca de los datos que aportaba sobre el resto de los artífices que trabajaron en la Capilla (pintores, escultores, doradores...) por las esporádica alusiones que realiza al reclamar su dinero. De esta manera sabemos que «tasso la pintura de Mantuano», también en relación con la obra del retablo (de la que no se tenía noticias documentales hasta la fecha) ${ }^{17}$ tasó, «la escultura de dos escultores, el ensamblaje de Sebastian de Benavente ${ }^{18}$, la talla de Pedro de

14 Ruiz Gómez, Leticia: La colección de estampas devocionales de las Descalzas Reales de Madrid, Madrid, 1998.

15 A.G.S., csr, leg. 193. Memoria de Tasación hecha por Pedro de Villafranca y Bartolomé Pérez. Apéndice II.

${ }_{16}$ Retablo que siempre se había considerado obra anónima o a lo sumo vinculada con Luisa Roldán o los Churriguera, para la bibliografía de este retablo: VV.AA.: Retablos de la Comunidad de Madrid siglos XV a XVIII, Madrid 1995, pp. 234-235.

${ }_{17}$ Ensamblador y tracista madrileño que concertó numerosos retablos, perdidos en su mayor parte y del que tenemos algunas noticias por Pérez de Villanueva, Joaquín: «Unos lienzos de Mateo Cerezo en el Convento de Jesús y María de Valladolid», B.S.A.A., tomo III, 1934-1935, p. 331. Agulló y Cobo, Merčedes: «Tres arquitectos de retablos del siglo XVII. Sebastián de Benavente, José de la Torre y Alonso García», A.E.A., 1973, p. 391. Agulló y Cobo, Mercedes: Documentos sobre escultores, entalladores y ensambladores del XVI y XVII, Valladolid, 1978.

18 Por otra fuente (A.G.S. csr, leg. 216) tenemos conocimiento de que a Pedro de Ávila, «escultor y al dorador» realizaron la puerta de acceso a la capilla puesto que se les pagó el 24 de julio del 1680: «50500 rs por la hechura de madera, dorado y demás aderentes de una reja puerta que de horden de SA quedo hecha para la $\mathrm{Ca}$ pilla que a devoción suya se hizo a Nra. Sra. del Milagro». Probablemente este escultor perteneció al linaje de escultores de los «Ávila», cuyo máximo exponente fue Juan de Ávila: Martín González, J. J.: Escultura Barroca en España 1600-1770, Madrid, 1991. 
Ávila ${ }^{19} y$ del Beneziano, el dorado de dos doradores) ${ }^{20}$, la zerrajeria de Filipin ${ }^{21}$ y del zerrajero de su Alteza, asta la obra del Platero ${ }^{22}$, marmolista, bidriero y solador; y no quisso tassar la de Pedro Sánchez zerrajero de camara porque agrego a su quenta obra echa para el convento con la de la capilla» ${ }^{23}$.

Por otras fuentes, podemos completar el elenco de artífices que trabajaron en la misma Capilla y también tener algunas noticias parciales de cómo se desarolló la obra. En primer lugar, sabemos que para su construcción fue necesaria previamente la compra y posterior cesión al Monasterio de una casa adyacente al convento para que sirviera de «habitación a las veatas de las Descalzas por las que se le quitaba para el sitio de la Capilla» ${ }^{24}$. En cuanto al encargado de la fábrica figura Joseph Gassen y Aznar ${ }^{25}$ como maestro de obras, tal y como reflejan las libranzas de pagos emitidas por el contador mayor de hacienda de don Juan, don Diego Velasco y Thomás Suarez ${ }^{26}$. Por su trabajo y compra de algunos materiales percibió «cinquentay nuebe mil reales», cantidades que fueron emitidas en varios pagos ${ }^{27}$. Por su parte, Pedro

19 Con respecto al retablo, contamos con más documentos que corroboran estos datos. En concreto, hemos localizado algunas libranzas que se emitieron para su construcción, por valor de un total de «cinquenta y tres mil ducientos reales». La primera del 22 de febrero de 1678 (por Decreto de SA del 17 del mismo mes), quatro mil reales para que socorriese al artifize que hizo el retablo para la capilla. Posteriormente y de forma consecutiva, a diversos oficiales que trabajaron en las obras y adornos de la capilla (el 1 y 30 de abril, el 19 de junio del 78) se les libraron Cuarenta y cuatro mil reales de vellon. Y lo que resulta más interesante es que el 26 de diciembre del mismo año se libraron cinquenta doblones de a dos escudos a don Joseph de Alcantara su ayuda de camara para que con ellos socorriese a Pedro de Abila, Sevastian de Benavente y Alonso Fernandez, maestros que havian travajado en la obra de la capilla de las Descalzas Reales de esta corte. (A.G.S. csr, leg. 208. D. Joseph de Alcantara ayuda de camara y guardajoyas de SA. Cargo de lo que se le libra para el retablo que se haze en la capilla de las Descalzas Reales de esta corte).

${ }_{20}$ Francisco Filipini, italiano, estuvo al servicio de la reina madre, doña Mariana de Austria, en calidad de relojero de camara.

21 Por la localización de algunas libranzas sabemos que se trata del Platero Dionisio de la Fuente, al que se le pagaron "ochocientos y noventa rs y medio de plata y mil y quinientos reales de vellon», estos últimos por el valor de la "echura de los candeleros que avia hecho para la capilla de las descalzas reales y el resto por resto de la plata que pesaron en mas dichos candeleros». (A.G.S., csr, leg. 208, Decreto del 20 de junio de 1679).

22 A.G.S., csr, leg. 193

23 A.G.S., csr, leg. 208. Figuran dos libranzas, una del 19 de julio del 1677 por valor de 130645 reales por la compra de la casa y otra fechada el 6 de agosto de dicho año en 850 reales por los derechos de la venta y compra. En definitiva todas las transacciones de compra y derechos de venta costaron un total de catorze mil quatrocientos y noventa y cinco reales de vellon.

24 Sobre este maestro de obras ver: Tovar Martín, V.: Arquitectos madrileños del siglo XVII, Madrid, 1975, p. 250. También Barbeito, José Manuel: El Alcázar de Madrid, Madrid, 1992.

25 A.G.S., csr, leg. 208. Joseph Gassen mro de obras de cassa de SA cargo de los mrs que se le libran para diferentes obras que hace de orden de SA desde 10 abril del 77 / Relación de las partidas de dinero que se han dado para la obra de la capilla de las Descalzas Reales de esta corte a diferentes personas en esta manera. Madrid 6 de abril del 79 .

${ }_{36}$ El primero el 29 de julio del 77 (por orden de SA del 26) le reportaron diez. mil reales de vellon ... por quenta de la obra que esta haziendo en las Descalzas Reales de esta corte. Pagos que continuaron el 22 de septiembre (por Decreto del 18), esta vez con ocho mil reales de vellon, el 9 de septiembre del 78 diez. mil reales de vellon (contralor el 5 de noviembre del 77). El 9 de diciembre del 77 (Decreto del 5) seis mil reales. El 14 de enero del 78 (por Decreto del 8) seis mil reales, el 22 de febrero del 78 seis mil reales, el 10 de abril del 78 cinco mil reales de vellon... El 19 de septiembre del 78 quatro mil reales de vellon ... para la satisfacion de unas piedras que se havian comprado para solar la capilla de las Descalzas Reales. Y finalmente el 6 de diciembre del 78 quatro mil reales de vellon. Todo sacado de A.G.S., csr, leg. 208.

27 A.G.S., csr, leg. 232 , cuaderno n..$^{\circ} 112$. Por una petición fechada el 23 de noviembre de 1680 por la mujer de Pedro del Sol que reclama 20700 reales. 
del Sol reclamaba cierta cantidad de dinero «que se le restan debiendo de la obra del chapitelito de las Senoras Descalzas Reales, asi en plomo, piçarras y otras cosas» ${ }^{28}$.

Finalmente, el pintor Francisco Rizi también consiguió que la Junta de Testamentaría reconociese su trabajo en la Capilla antigua del Milagro y le librara el 30 de abril de 1681, en alhajas de la almoneda, «Doscientos y setenta y un mil quinientos y siete maravedis de vellón» que se correspondían con las «cinco mil y trescientos rs de vellon» del importe de las pinturas tasadas por Villafranca y Bartolomé Pérez, y los «dos mil seiscientos y ochenta y seis reales» del cargo de pintor que reclamaba (conjuntamente, hacían un total de «siete mil nuevecientos y ochenta y seis reales de vellon» ${ }^{29}$. Igualmente consiguió que el 26 de mayo de 1683 se le pagasen: «120784 maravedis» por tasar las pinturas de la almoneda de don Juan ${ }^{30}$. Junto a estas satisfacciones económicas, resulta de gran interés el comprobar cómo entre las exigencias propuestas por Francisco Rizi figurará la reclamación de los instrumentos de pintor de don Juan de Austria ya que llegó a «suplicar a los señores de la Junta de Testamentaria y descargos se sirban de mandarle dar todos los despojos de pintor, que por fin y muerte del señor don Juan quedaron entre sus bienes, por aver sido su Pintor de Camara y pertenezerle por este titulo».

ELVIRA GONZÁLEZ ASENJO Universidad Complutense

APÉNDICES I, II Y III: A.G.S., csr, leg. 193.

\section{APÉNDICE N. ${ }^{\circ}$.}

Memoria de don Dionissio Mantouano Pintor de su Magd. Tocante a las Ssras

Descalças Reales.

Memoria de lo atrasado por al colocacion de N.Sra del Milagro en su Capilla Nuoba nel Real Conbento de las señoras Descalças Reales de los adornos de afuera de la sudha Capilla nueba hechos d'orden de SA el Sr Don Juan de Austria que goçe de gloria.

Primeramente las dos prospetivas en los dos testeras del balcon de hierro que mira nel patio del refetorio que son pintadas al fresco y puesto encima de una una campanilla da truenos con los hierros dorados a fueogo monta todo seycientos Reales (Ou-600)

Mas de haver renovado la Capilla Vieja de N. Sra del Milagro que sirve ahora a N. Sra de la Concepcion, pintada al fresco y al olio con un nichio nuobo pintado y la peana de nuobo hecha dorada y pintada y

haver compuesto l'Altar con (a)lacenas y añadir a los lados dho altar y dorado los filetes de nuobo todo monta ducientos ducados $(2 \mathrm{u}-200)$

Mas todos los adornos de dha Capilla por la parte de afuora de diferentes jaspes verde de tortosa y con los enbotidos de l'apis azuli con las vetas de oro fino y corre todo el rodapies alrededor de la Capilla de N. Sra de la Assunsion que todo es ventitres varras todo dado de vernice y es una varra de alto con unas arandelas de ooha de lata con sus pernios puesto en la pared e todo monta trecientos ducados ( $3 \mathrm{u}-300$ ) ?

Que todo monta seys mil y cien R. de vl que es lo que se debe a Dionisio Mantuano Pintor de su Magd. (6u-100)

28 Como consta igualmente en la carta de pago que se le emite el 12 de mayo de 1681. A.H.P.M., Protocolo 11789, folio 210r-210, Apud, Barrio Moya, J. L.: «Los bienes del pintor Francisco Rizi», A.E.A., 1983, pp. 39-46. Siendo uno de los testigos el pintor Isidoro de Arrendondo.

29 Tal y como figura en la carta de pago firmada por el propio Rizi y emitida por la Junta el 9 de junio de 1683, A.H.P.M., Protocolo 11789, folio 617r. 


\section{APÉNDICE N. ${ }^{\circ}$ II.}

Memoria de la tasacion que emos echo por la testamentaria de su Alteça que esta en gloria de orden de las señoras Descalzas Reales:

- Primeramente dos prespetibas en el balcon pintadas a el fresco y poner unos yerros a una campanilla dorados a fuego bale quinientos rs de vellon 0500 .

- Mas el adereço de la capilla biexa que se pinto de las cornisas abaxo y adereço de ventana y dorado y pintado de la peana de N. ${ }^{\text {a }}$ Señora de la Concepcion bale mil y quinientos 1500 .

- Mas del adorno de dicha capilla por la parte de afuera y beinte y tres baras de rrodapies de una barra de alto bariado de xaspes de tortosa y berdes con enbutidos de lapizlazuli y benas de oro barniçados y de quatro arandelas de oja de lata con sus pernios balen 01914. Que todo esto monta tres mil nobecientos y catorçe reales de vellon 3914. Y lo tasamos asi a 25 de abril de 1681. (Firmas de) Joseph Donoso, Claudio Coello.

\section{APÉNDICE N..$^{\circ}$ III.}

Tasacion En la Villa de Madrid a diez y ocho dias del mes de nobiembre año de mil y seiscientos y ochenta ante mi el presente escrivano parecieron oi dia de la fha Pedro de Villafranca y Bartolome Perez Vezino de esta Villa y Mros del arte de Pintura y dijeron y delcararon que haviendo visto y reconoicdo de pedimento de Dn Francisco Rizi Pintor de Su Magestd y de Camara de su Alteza, unos quadros que estan en un oratorio de Nra Sra del Milagro zita en el Real combento de las Sras Descalzas Rs desta villa que dentro del dho oratorio estan nuebe que el uno sera como de siete quartas de alto en el esta pintada una ymajen de Nra Sra San Juan y la Magdalena el qual dijeroú que tassan a su saber y entender en setecientos Rs de vellon y junto a este dho quadro estan los diferentes de la pasion de Nro Señor Jesuchristo. Los quales asi mismo los tasan a Ducientos Rs vellon cada uno; Y ansi mismo an visto y reconocido otros seis quadros de diferentes santos que estan fuera del dho oratorio pintados al olio en la pared que haze paso al dho oratorio que tendran cada uno de alto como siete quartos los quales tasaron cada uno a quinientos Rs de vellon que es la Verdad en lo que los tasan y declaran ante mi el Ess(criva)no y lo firmaron de sus nombres de que di fee= y de la Camara de Su Alteza. =valga=. (Firmas) Pedro de Villafranca y Bartolome Pérez...Juan López de Monesterio ess(criba)no del rey nuestro señor. 